\section{Enhanced Mid-Latitude Tropospheric Warming in Satellite Measurements}

\author{
Qiang Fu, ${ }^{1,2 *}$ Celeste M. Johanson, ${ }^{1}$ ]ohn M. Wallace, ${ }^{1}$ Thomas Reichler $^{3}$
}

B oreal summers that follow strong $\mathrm{El}$ Niño events, like the one that occurred in 1997, are often characterized by anomalous tropospheric warmth in mid-latitudes of both the Northern and Southern Hemisphere. This warmth occurs in response to El Niño/ Southern Oscillation (ENSO)-induced, positivesea-surface temperature (SST) anomalies in the Indian and western Pacific Ocean "warm pool" regions (1). The anomalous mid-latitude tropospheric warmth is accompanied by an elevation of the pressure surfaces in the upper troposphere and an increased frequency of droughts, including in parts of the United States $(1,2)$.

From 1979 onward, the most pronounced SST warming has occurred within this same "warm pool" region (3). If the planetary-scale atmospheric circulation responds to the multidecadal SST trends in the same way as it responds to ENSO-induced SST variability, one might expect to observe a multidecadal trend toward a warmer mid-latitude troposphere.

We examined atmospheric temperature trends for 1979 to 2005 based on satellite-borne microwave sounding unit (MSU) data (4-6). Figure 1 shows the global spatial patterns of strato-

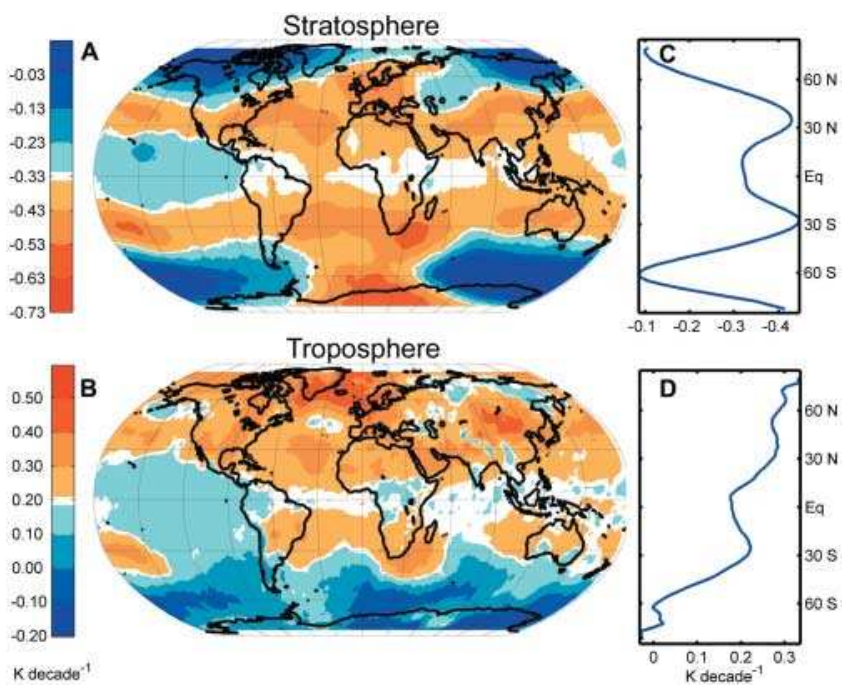

Fig. 1. Global and latitudinal distributions of atmospheric temperature trends for 1979 to 2005 based on satellite-borne MSU observations. (A and C) Stratospheric trends with a global mean of $-0.33 \mathrm{~K}$ per decade. (B and D) Tropospheric trends with a global mean of $+0.20 \mathrm{~K}$ per decade. Orange shading represents enhanced rates of stratospheric cooling and tropospheric warming relative to their respective global means, and blue shading represents suppressed rates. The polarity is reversed to facilitate comparison between (A) and (B). spheric and tropospheric temperature trends for gradients in the trends, the reference (white) values in the color bars in (Fig. 1, A and B) are The most pronounced feature is the enhanced stratospheric cooling and tropospheric warming spheres, relative to other latitudes. The atmospheric trends for 1979 to 1997 (fig. S1) exhibit dicates that existence of the trend is not contingent on the episode of record-high mid-latitude response to the $1997 \mathrm{El}$ Niño (1) but is a robust feature of the period of record from 1979 onward (fig. S2). The same pattern is evident in the trend in radiances from MSU channel 2 (fig. S3), which is a further proof of the enhanced midlatitude tropospheric warming corresponding to the enhanced stratospheric cooling

Unless it is compensated by a drop in sealevel pressure in the same latitude belt, the observed pattern of temperature changes in Fig. 1 is indicative of a tendency toward an upward bulging of the upper tropospheric pressure surfaces centered around $30^{\circ}$ latitude in both hemispheres. Because $30^{\circ}$ latitude corresponds to the latitude of the tropospheric jet streams, it can be inferred that the downward slope of the pressure surfaces toward the poles has been increasing on the poleward flanks of the jet streams and decreasing on the equatorward flanks. Such a reshaping of the pressure surfaces would have the effect of shifting the jet streams poleward. Based on the observed temperature changes alone, we estimate that the jet streams in both hemispheres have shifted poleward by $\sim 1^{\circ}$ latitude in both summer and winter seasons (6). Because the jet streams mark the poleward limit of the tropical Hadley circulation, systematic poleward shift of the jet streams implies that the tropical circulation has widened by $\sim 2^{\circ}$ latitude during this 27 -year period (7). (Our analysis of the National Centers for Environmental Prediction/National Center for Atmospheric Research reanalyses suggests that sea-level pressures near $30^{\circ} \mathrm{N}$ and $30^{\circ} \mathrm{S}$ have risen relative to surrounding latitudes. Such pressure rises, if real, would cause an additional poleward shift in the jet streams.)

In contrast to the seasonally dependent circulation changes reported in association with the Northern and Southern Hemisphere annular modes, the changes reported here are occurring at somewhat lower latitudes, and the Northern Hemisphere trends are no less pronounced during the warm season (fig. S4) than during the cold season.

Whether the observed trends in Fig. 1 are an integral part of the response to greenhouse warming remains to be seen $(8-10)$. Regardless of the cause, the poleward shift of the jet streams and the associated subtropical dry zone (11), if it continues, could have important societal implications.

\section{References and Notes}

1. N. C. Lau, A. Leetmaa, M. J. Nath, H. L. Wang, J. Clim. 18, 2922 (2005).

2. M. P. Hoerling, A. Kumar, Science 299, 691 (2003).

3. T. M. Smith, R. W. Reynolds, J. Clim. 18, 2021 (2005).

4. C. A. Mears, M. C. Schabel, F. J. Wentz, J. Clim. 16, 3650 (2003).

5. Q. Fu, C. M. Johanson, S. G. Warren, D. J. Seidel, Nature 429, 55 (2004).

6. Materials and methods are available as supporting material on Science Online.

7. T. Reichler, I. Held, paper presented at the 17th Conference on Climate Variability and Change, Cambridge, MA, 13 to 17 June 2005.

8. State-of-the-art coupled ocean-atmospheric models predict stronger warming in the tropical troposphere than in mid-latitudes (9) and a poleward shift of the eddy-driven jets centered $\sim 45^{\circ}$ latitude (10). A pattern like the recent trends, with strongest tropospheric warming centered $\sim 30^{\circ}$ latitude, is not recovered in the simulations.

9. J. T. Houghton, Climate Change 2001: The Scientific Basis (Cambridge Univ. Press, Cambridge, 2001).

10. S. S. Leroy, ]. G. Anderson, ]. A. Dykema, paper presented at the 18th Conference on Climate Variability and Change, Atlanta, GA, 28 January to 3 February 2006.

11. S. D. Schubert et al., J. Clim. 17, 485 (2004).

12. This study is supported by the National Oceanic and Atmospheric Administration grant NA17RJ1232 and NASA grant NNG04GM23G. We thank D. L. Hartmann and J. Paegle for useful discussions.

Supporting Online Material

www.sciencemag.org/cgi/content/full/312/5777/1179/DC1

Materials and Methods

Figs. S1 to S4

References

30 January 2006; accepted 30 March 2006 10.1126/science. 1125566

${ }^{1}$ Department of Atmospheric Sciences, University of Washington, Seattle, WA 98195, USA. ${ }^{2}$ College of Atmospheric Sciences, Lanzhou University, Lanzhou, Gansu, 730000, China. ${ }^{3}$ Department of Meteorology, University of Utah, 135 S 1460 E, Room 819 (WBB), Salt Lake City, UT 84112-0110, USA.

*To whom correspondence should be addressed. E-mail: qfu@atmos.washington.edu 


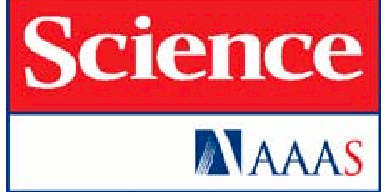

\section{Supporting Online Material for}

\section{Enhanced Midlatitude Tropospheric Warming in Satellite Measurements}

Qiang Fu,* Celeste M. Johanson, John M. Wallace, Thomas Reichler

*To whom correspondence should be addressed. Email: qfu@atmos.washington.edu

This PDF file includes:

Materials and Methods

Figs. S1 to S4

References 
Material and Methods

1. MSU data and retrieval scheme

We used MSU channels 2 and 4 gridded $\left(2.5^{\circ}\right.$ by $\left.2.5^{\circ}\right)$ monthly anomaly brightness temperature data compiled by the RSS team $(S 1)$ from January 1979 to December 2005. The stratospheric temperature trends are directly derived from channel 4. The global distribution of tropospheric temperature trends is derived from a linear combination of channels 2 and 4 following $(S 2)-(S 3)$ with explicit consideration of the tropopause height dependence on the latitude $(S 4)$. Note that the enhanced midlatitude tropospheric warming belts can be also inferred from the RSS $\mathrm{T}_{2 \mathrm{LT}}$ data $(\mathrm{S} 5)$.

2. Estimating the shift of the jet stream

The latitudes of the jet streams in 1979 and 2005 are inferred from the geostrophic equation, as applied to north-south profiles of zonally-averaged geopotential height of the $200 \mathrm{hPa}$ pressure surface. To obtain the 1979 and 2005 200-hPa height profiles, the timemean 1979-2005 profile based on the NCEP/NCAR reanalyses is perturbed by subtracting and adding the north-south profile of 200-hPa height trend multiplied by 13.5 years. The north-south profile of $200-\mathrm{hPa}$ height trend is inferred from zonal averages of the MSU-derived tropospheric temperature trends, as applied to the 1000-200-hPa layer. Jet stream positions were estimated by applying a 9-point cubic polynomial best fit to the zonally averaged geostrophic wind profiles to derive continuous curves from the grid point data, which are defined at $2.5^{\circ}$ increments of latitude. 
Figure S1
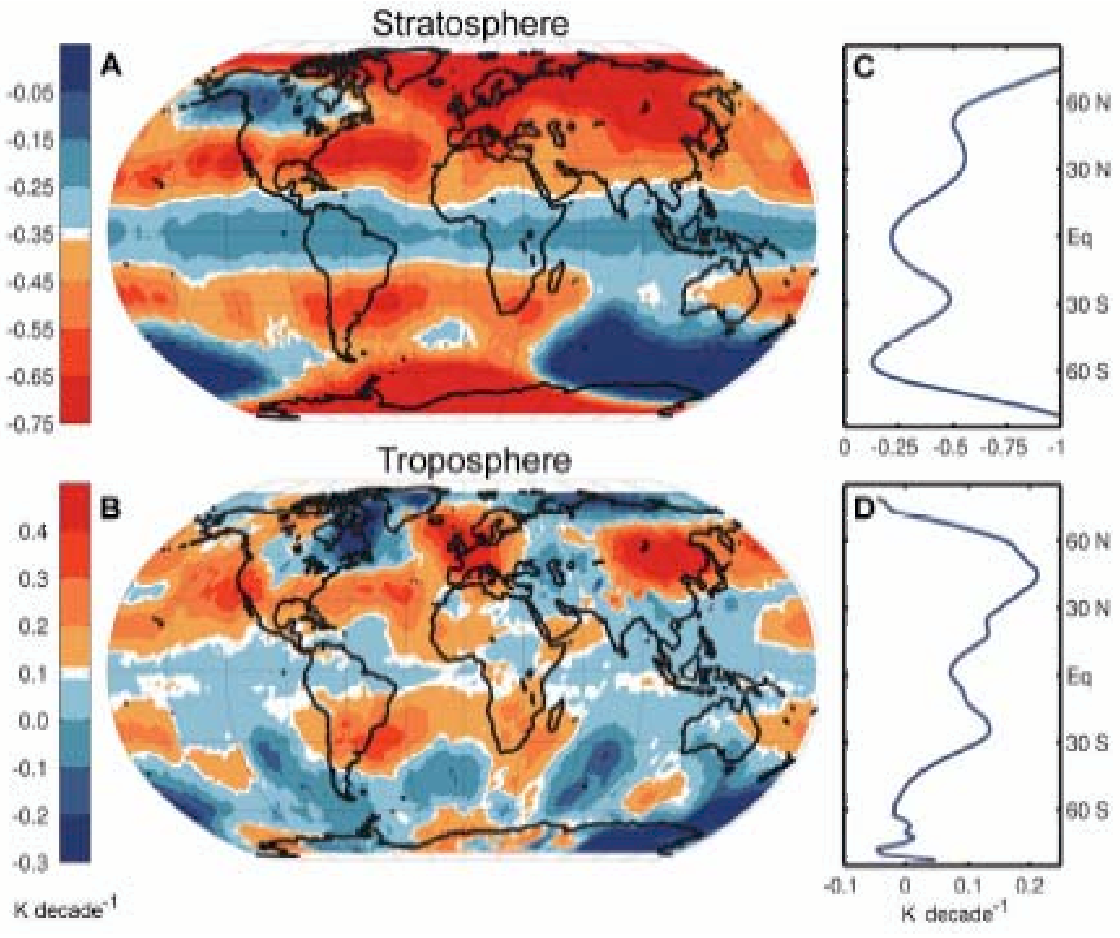

Fig. S1. Same as Fig.1 but for 1979-1997. 
Figure S2
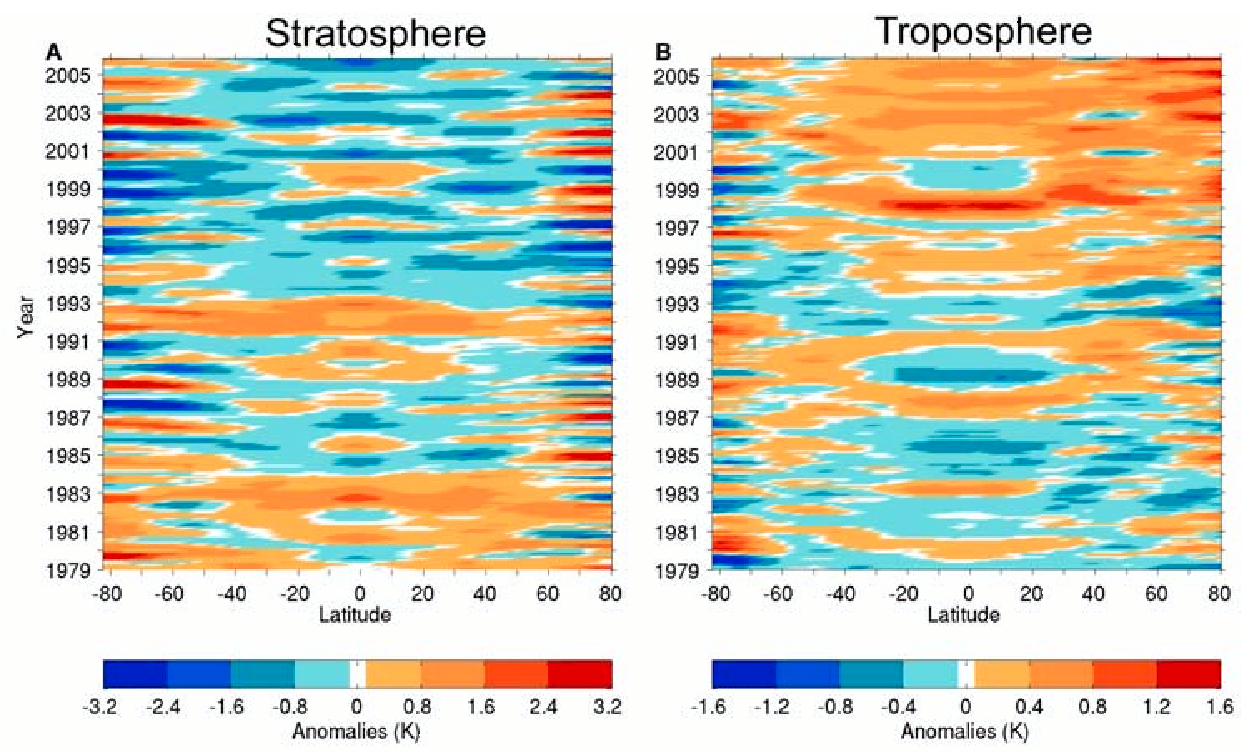

Fig. S2: Time evolution of the zonal mean temperature monthly anomalies in (A)

Stratosphere and (B) Troposphere. The anomalies are relative to climatological monthly means over 1979-1998 (these anomalies were smoothed by applying a 5-month running mean). The natural influences including both ENSO and volcanic eruptions modulate the evolution of the patterns but do not drive the overall trends for 1979-2005. 
Figure S3

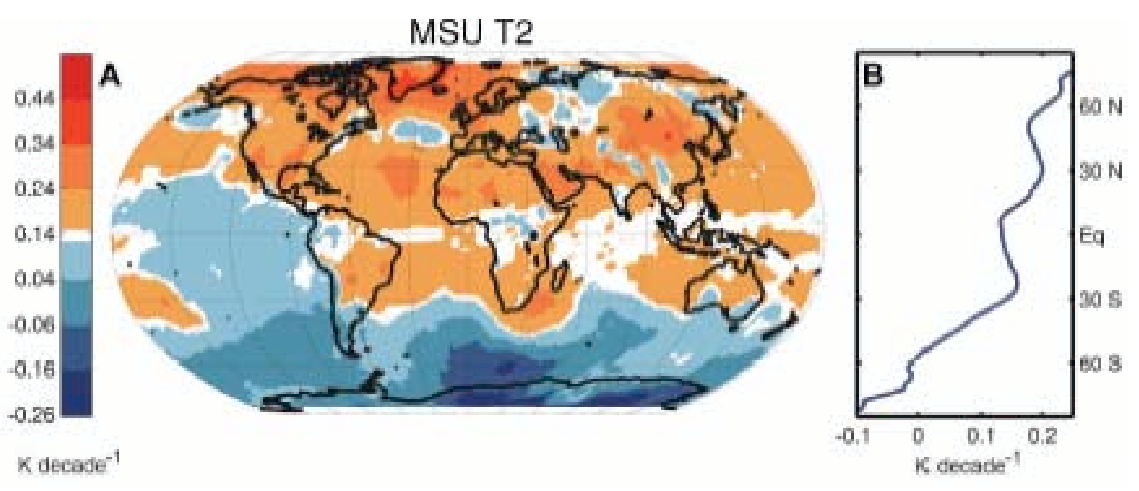

Fig. S3. Global and latitudinal distributions of MSU channel 2 (T2) trends for 1979-2005. 
Figure S4
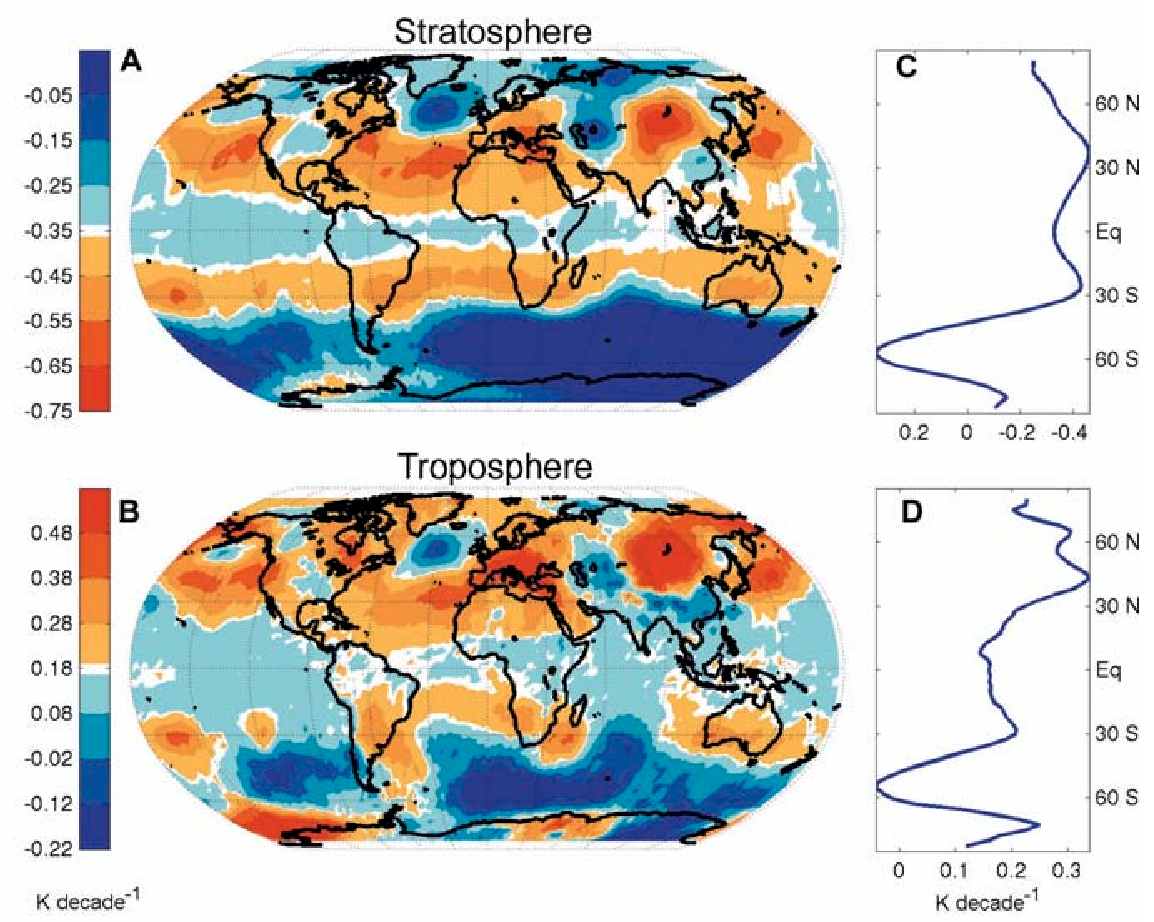

Fig. S4. Same as Fig. 1 but for the boreal summer season (June, July and August). The color bar in (A) is centered at $-0.35 \mathrm{~K} /$ decade which is the average trend from $60 \mathrm{~S}$ to $90 \mathrm{~N}$. 
References and Notes

S1. C.A. Mears, M.C. Schabel, F.J. Wentz, J. Clim. 16, 3650 (2003).

S2. Q. Fu, C.M. Johanson, S.G. Warren, D.J. Seidel, Nature 429, 55 (2004).

S3. Q. Fu, C.M. Johanson, Geophys. Res. Lett. 32, 1029/2004GL022266 (2005).

S4. C.M. Johanson, Q. Fu, J. Climate 19 (2006, in press).

S5. C.A. Mears, F.J. Wentz, Science 309, 1548 (2005). 